of this study, of which 53\% $(n=17 / 32)$ were term and $47 \%$ $(n=15 / 32)$ were preterm babies. One third $(67 \%, n=79 / 118)$ of these samples were preterm. Only $0.3 \%(n=4 / 118)$ samples were taken from babies not currently admitted to NICU.

$3 \% \quad(n=4)$ of cases both HHGMD/blood gas results were same while in $6 \%(n=7)$ of cases HHGMD result was lower than the blood gas result. However in 107 cases HHGMD result was higher than blood gas result with a mean difference of $1.07 \mathrm{mmol}(95 \%$ CI $0.94-1.15, \mathrm{p}<0.05)$ glucose per sample tested

Conclusions A mean difference of approximately $1 \mathrm{mmol} / \mathrm{L}$ glucose between both measurement devices on the same blood sample has potential clinical and economic significance particularly in our population where hypoglycaemia and subsequent neonatal unit admission is common. A more robust way of standardising glucose measurement is required in this cohort of babies.

\section{G382(P) RADIATION EXPOSURE IN NICU}

V Venkatesh, AVAlladu Venkata. Women and Children, Neonatal Care and Research Institute, Bengaluru, India

\subsection{6/archdischild-2018-rcpch.371}

Aims To reduce the radiation eposure in babies admitted to a singe tertiary centre by reducing the number of duplicate $\mathrm{X}$ rays taken from $30 \%$ to 0 within a period of 6 weeksand by increasing the use of point of care ultrasound to detect the tip of the UVC from $0 \%$ to $80 \%$.

Methods We used the USAID quality improvement process for the study.This involved the use of process map and fish bone analysis,retaining of staff and testing of changes(use of 2 personnel method to take $\times$ ray)was implemented.

Results The number of duplicate $\times$ rays decreased from $30 \%$ to $8 \%$ over a period of 3 months.Similarly the use of point of care ultrasound also increased for the detection of UVC tip from $0 \%$ to $70 \%$.

Conclusion Retraining of the nursing staff to take $\times$ rays, implementation of systemic changes in the procedure of taking $\times$ rays resulted in the reduction in the number of duplicate $\times$ rays from $30 \%$ to $8 \%$ thereby leading to improvement in the care that we provide to sick newborns in a resource limited setting.

\section{G383(P) AN INNOVATIVE METHOD OF GATHERING FEEDBACK AS PART OF THE 'WHAT MATTERS TO YOU?' MOVEMENT}

S Gabbie, V Dublon, R Levi, I Runnacles. Paediatrics, Royal Free NHS Trust, London, UK

\subsection{6/archdischild-2018-rcpch.372}

Aims Increasing user feedback and co-production are a priority of the National and Trust agendas. Our aim was to gather feedback, opinions and constructive suggestins from parents and young people in an interactive, fun and informal environment. This was part of a National Initiative in which departments devised their best method of establishing 'What Matters To You?'

Methods We designed a feedback morning with a variety of activities. The full multidisciplinary team were involved including doctors, nurses, education, play, ward clerks and housekeeping teams. This enabled children of all ages and their carers to provide feedback in real time, both verbally and in writing. Tools used included 'pants and tops' feedback clothes lines, knitting lessons from the Royal Free volunteers, raffles, games and home made cakes.

We asked people specific questions using a mini structured interview. These included, 'what matters to you in your life? What matters when you come to hospital? What has and hasn't gone well? What would you change and how?'

Results There were 50 attendees including patients, carers and staff. All contributed to feedback in different formats which was largely positive. Parents and young people valued the opportunity for face to face conversation and suggestions for service development.

Qualitative results were grouped under headings, General, Attitudes, Listening, Staff, Systems.

Examples of comments and actions taken include:

'The nurses and doctors are all so kind and caring. They make you feel at ease and do an amazing job'

'Able to come to school/be in education while getting support for eating disorder'

'Try and support patients with a language barrier' - we have increased use of and access to language line.

'To be listened to and for my views to be taken into consideration in any decision' - we have highlighted and embedded use of parental concern into PEWS scores and safety huddles.

'First contact when arriving at the hospital is very important' - in our ward refurbishment we have moved the reception desk to the front door so as to welcome patients in.

Conclusion This event improved dialogue and openess between staff and familes. We recommend other departments undertake a similar approach in order to identify what matters most to patients.

\section{G384(P) INTRODUCTION OF A NOVEL JUNIOR DOCTOR -LED PROLONGED JAUNDICE CLINIC IN ORDER TO REDUCE THE WAIT TIME FOR RAPID ACCESS CLINIC APPOINTMENTS WITHIN THE PAEDIATRIC DEPARTMENT}

${ }^{1}$ B Bassoy, ${ }^{1}$ W Zaw, ${ }^{2} S$ Beech, ${ }^{2} \mathrm{C}$ Warlow. 'Paediatric Department, Northampton General Hospital, Northampton, UK; ${ }^{2}$ Quality Improvement, Northampton General Hospital, Northampton, UK

\subsection{6/archdischild-2018-rcpch.373}

There has been an increasing demand for rapid access clinic appointments in the Paediatric department in Northampton General Hospital over the past 2 years, which has led to an increase in wait time for an appointment. (21 patients per month on average in 2015 and 34 per month in 2016). This rapid access clinic is led by a consultant, and runs up to two times per day.

A large proportion of the patients seen in this clinic have prolonged jaundice, and can be managed by a junior doctor. Therefore, our proposal is to introduce a junior doctor led clinic to see patients with prolonged jaundice, to free up more space in the consultant-led rapid access clinic. The overall aim of the project was to reduce the average wait time for the paediatric hot-clinic to below 2 days by December 2017.

Training on running the clinic, using a new proforma, was delivered to support the junior doctors with the new clinic. A process was established to ensure all investigations undertaken after the appointment were discussed with the Consultant of the Week. A 